\title{
Analyses on the Way of Changing the Growth Mode of Circulation Economy
}

\author{
Ping Jia \\ School of Management, Xuzhou Normal University \\ Tel: 86-516-8088-0165 E-mail: yybaolin@163.com \\ Zhi Dong \\ School of Foreign Studies, Xuzhou Normal University \\ Tel: 86-516-8088-0165
}

\begin{abstract}
Based on the theory of growth mode in circulation economy, this article analyses current situation and problems of China's commodity circulation. It describes the impact of improving the level of logistics management on changing the growth mode of circulation economy from the perspective of logistics time value, location value and circulation processing value. It brings forward that improving the level of logistics management is the based way of changing the growth mode of circulation economy. It finally brings forward suggestions on improving the level of logistics management among enterprises.
\end{abstract}

Keywords: Circulation economy, Growth mode, Logistics management

\section{Introduction}

In the report of the 17th National Congress of the CPC, General Secretary Hu Jintao put forward acceleration of transforming the mode of economic growth and promotion of optimizing and upgrading industrial structure. Having relation to national economy, this is an urgent and important strategic task. It is needed to insist on a new-type way of industrialization, and stick to expanding domestic demands, particularly the principle of consumer demands. The way of promoting economic growth is changed from mainly relying on investment and export to relying on the coordination of consumption, investment and export; from mainly relying on the secondary industry to relying on the coordination of the primary industry, the secondary industry, and the tertiary industry; from mainly relying on increased consumption of material resources to relying on technological development, improvement of labor quality and management innovation." Although China has made great progress in changing the mode of economic growth for many years, the fundamental change has not got achieved overall. A prominent problem in China's economic and social development is still the extensive mode of economic growth. It embodies in the realization of rapid economic growth through enlarging investment scales and large consumption of various resources, which results in low efficiency, low benefits, serious environmental pollution and un-sustainability of the development.

Since the reform and opening-up, China has formed a pluralistic and multi-level circulation system that widens the scale of circulation. But the growth of the circulation economy is mainly extensive, economic efficiency is not high, and there is fierce competition in the circulation industry. The famous economist, Professor Liu Guoguang mentioned that circulation has changed from the end of the industry to the leading industry. Therefore, it is urgent to change the growth mode of circulation economy.

\section{Theoretical analyses on the change of growth mode of circulation economy}

The concepts of the "extensive growth" and the "intensive growth" were introduced into China from the Soviet Union in 1960s. Prior to this, although the concept of the mode of economic growth had not been used in China's economic circles, a lot of analyses were made towards various low efficiency and high waste in the process of economic growth. Since then, especially in 1979-1980, the issue of the mode of economic growth fully got discussed in China. And the concept of the mode of economic growth was extensively used after the Fifth Session of the $14^{\text {th }}$ Central Committee of 
the CPC. For the mode of economic growth, it is accepted and categorized as the extensive economic growth and the intensive economic growth from the perspective of production inputs factors by current theoretical circles. The extensive form of economic growth is to increase the number of products and to promote the mode of economic growth by mainly relying on funding increase and resources input. The basic characteristics are that economic growth is realized by adding and inputting a large number of production factors. That is to achieve it by investing a large amount of funds, using a large scale of labor, and consuming massive raw materials and energy. The intensive form of economic growth is to increase the number of products and improve product quality by mainly relying on scientific and technological progress and labor quality improvement. The basic characteristics are that, to a large extent, economic growth is promoted by driving forces of technological innovation, human resource accumulation, resources transfer, economies of scale and learning effect.

In order to take economic efficiency as the center and to improve the performance of the national economy, circulation industry is required to achieve the economic growth by means of transforming the extensive form of economic growth to the intensive one. The growth mode of commodity circulation is a mode of input, combination and use of various business elements in the field of commodity circulation. It has close relations with its level of productivity, circulation development strategies, level of circulation management and commodity circulation system of China's national economy. From the point of view of inputting the circulation elements, the growth mode of commodity circulation is divided into the extensive growth and the intensive growth. The intensive growth of commodity circulation is to increase the production value of circulation and to achieve the growth of commodity circulation through element increases of capital and labor in commodity circulation. This is a kind of growth mode with high cost, more circulation links, slow turnover and poor efficiency. The intensive growth of commodity circulation is market-oriented and takes the benefits of circulation economy as its center. By improving the efficiency of using various elements, it speeds up the turnover of circulation capital and saves circulation cost in order to increase sales and achieve the growth of commodity circulation. The realization of changing the extensive growth of commodity circulation to the intensive one should pay attention to the following: depending on the efficiency improvement of commodity circulation, reducing circulation costs, speeding up capital turnover of commodity circulation, and improving circulation efficiency and effectiveness.

\section{Analysis on current situation and problems of China's Commodity Circulation}

China's value-added mode of circulation economy is extensive for a long time, for example, slower turnover of circulation capital, slower speed of logistics, higher cost of circulation, higher commodity stocks and serious waste in circulation. It is reported that the loss rate of China's fruits, vegetables and other agricultural and sideline products reaches $25 \%-30 \%$ in logistics, while the loss rate of fruits and vegetables in the developed countries is only $5 \%$. The logistics costs of China's agricultural products usually account for 30\%- $40 \%$, and fresh goods is more than $60 \%$. But in developed countries, logistics costs are about $10 \%$ of the total in general. In 2002, the contribution of China's circulation industry to the GDP was $7.8 \%$, while in the United States, Japan, Britain, France and other developed countries, the number had made a reach over $15 \%$ in the middle of 1990s. Still in the same year, the proportion of employment in China's tertiary industry was $28.6 \%$, among which the proportion of employment in wholesaling, retailing and catering was $6.7 \%$, far below the average level of developed countries.

\subsection{A large number of enterprises, small scales and low level of systematization}

The majority of circulation enterprises in China are operated in localization, which lack of large nationwide retailing businesses, and lack of enterprises of international standards. Circulation enterprises in China are significantly regional. It is relatively limited in scale and in space of development; thus the scale of the overall assents is small and they do not have the capacity of rapid expansion. For instance, Wal-Mart's total global sales was 278.08 billion U.S. dollars in 2003. But Shanghai Bailian Group, being as the largest commercial enterprises in China, only had the total sales of 48.52 billion RMB in 2003. The total sales of Wal-Mart was 476 times than the one of Shanghai Bailian Group. And their low level of systemization results in the incapability of meeting the development requirements of large-scale production. The existence of lots of small circulation enterprises makes the allocation of resources in circulation duplicated and inefficient. And in order to survive, they tend to take unfair competition means, which causes chaos in the field of circulation, affects resources utilization, and has impact on the growth of circulation economy.

\subsection{Low level of management in circulation enterprises, serious extensive phenomenon}

Take the logistics enterprises in Xuzhou for instance. The main storage resources of Xuzhou in 2005 were about 139,400 square meters, but the actual utilization rate is not high. The existence of decentralized inventory, duplicated inventory and multi-level inventory leads to a vicious circle of increased inventory costs, increased funds, more inventory links, longer production cycle and low economic efficiency. The allocated equipments inside logistics industry are outdated. There are many logistics facilities and equipments that businesses own, but the utilization rate is generally low. Although there are various types of freight vehicles 26,997 and 4,890 ships, the idle rate is high. It is common that the phenomenon of unfair competition exists, such as more waiting time between cars and goods, overloading, over speed and forcing down the price. The logistics cost of most manufacturing enterprises accounted for 
$20 \%$ of the total, alarming the waste of resources. Most manufacturing enterprises with a certain scale have their own fleet and warehousing facilities, but the rate of utilization is not high and external services are not professional; thereby it results in the urgent needs of the market on the one hand, a lot of idle logistics capacity on the other hand. Logistics enterprises are small in scale, single in function, low utilization of facilities, unreasonable layout, more redundant projects, backward management, and idle capital. It leads to high cost of logistics and heavy losses. According to expert's estimation, the national logistic consumption is more than 300 billion RMB. Materials cannot be deployed timely, leading to a large amount of inventory.

\subsection{Low technology of the circulation enterprises}

Take the logistics industry for instance, the low technological content of China's logistics industry is mainly reflected in the following aspects: from the aspect of storage technology, it is mainly in manual work with low efficiency; from the aspect of information system construction in logistics management, the progress is slow; from the aspect of establishment of international logistics standards, development lags behind; from the aspect of transportation facilities, the level of modernization is low, and so on. The low level of information in circulation leads to high cost and low efficiency, resulting in the phenomenon that the current circulation industry in China is still a labor-intensive industry. For example, it is reported that there is only $6.48 \%$ enterprises using e-commerce. Information investment by circulation enterprises is less than $2 \%$ of the total, having a large gap compared with the average level of $8 \%-10 \%$ among large foreign enterprises. The low level of information directly or indirectly affects the speed of cash flow and the improvement of profit margin.

\section{Impact of improving the level of logistics management on changing the growth mode of circulation economy}

The transformation of the growth mode of commodity circulation economy is a complicated systematic project, which needs works from government, industry and enterprises. This article only discusses from the aspect of improving the logistic managerial level by the level of logistics enterprises.

With the development of social division of labor and the increase in total social products, especially together with the economic globalization and the development of information technology, logistics has rapidly developed, and has become a very important component in the socio-economic development. It has extensive and far-reaching impact on the operation mode of traditional commercial, commodity circulation patterns and people's lifestyle. And logistics industry will become an important industry and new economic growth point in economic development of $21^{\text {st }}$ century. The improvement of logistics managerial level reflects on creating logistics time value, location value and processing value through high efficiency and low cost.

\subsection{Impact of logistics time value on the growth of circulation economy}

The logistics time value is that materials have a time difference between the supplier and the demander. To change the time difference is to create value. Shortening time may reduce logistics losses and lower logistics consumption. It may increase the turnover rate of goods liquidity and improve the rate of commodity circulation. In addition, logistics is a kind of business activities to send commodity at the right time to the right place. It is an important way of improving the efficiency of commodity circulation and is "the source of the third profit". In 2003, the average turnover rate among the top 500 enterprises in China was 2.4 times per year, while businesses in developed countries the highest number is more than 20 times. In 2002, the profit margin of Wal-Mart was 3\%, while in China, the profit margin of the top 500 enterprises was averagely $1.06 \%$.

\subsection{Impact of logistics location value on economic growth}

The logistics location value is that materials have a space distance between the supplier and the demander. Value is created because of the space changing. The process of creating logistics location value needs handling, storage, transportation and other logistics links. Industrial goods are moved from factory to consumers through handling, storage and transportation. At present, the circulation cost usually takes $50 \%$ of commodity prices in China. And the number in fruits, vegetables and some chemical products may reach $70 \%$ sometimes. In the production of automotive parts in China, more than $90 \%$ of the time is taken in handling, storage and transportation. Currently, the logistics costs in China are over $20 \%$ in the proportion of GDP, one time higher than the average level in developed countries. Logistics enterprises in China should fully use advanced technology and managerial methods, and create logistics location value by improving logistics efficiency and reducing logistics costs.

\subsection{Impact of added value of logistics circulation processing on economic growth}

An important characteristic of modern logistics is to take a certain added processing activities in accordance with its own advantages, which will form added value of the target labor. It improves added value to goods, increases the output in circulation industry, and promotes economic growth. In the process of circulation, it is needed to fully consider technological progress, study on the adoption of collection equipment and specialized shipment, rather than using a processing that is not achieved in circulation; and study on transportation technology of less packaging, lower 
packaging costs.

\section{Considerations on improving the level of logistics management}

\subsection{Adopt chain operation to integrate small and medium-sized logistics enterprises}

Introducing the organizational form of chain operations into the logistics industry is to achieve the intensive organizational form among logistics enterprises. Through chain operation, the whole large-scale logistics management is required to organically integrate with the real decentralized logistics activities. Many small and medium-sized logistics enterprises are organized together as a community of interests. They perform synergetic advantages from a number of functions so as to realize logistics information sharing, high efficiency of coordination and expansion of the market coverage, and to achieve economies of scale. For instance, Jin Cheng International Logistics started from a small little-known freight forwarding company. At present, it becomes a leading company among private enterprises in China. Only using a short period of 15 years does it create a myth that a logistics enterprise in China adopted strategic transformation and quickly grew up. Its secret of the development is to use "chain" as a means of the distribution network, and it puts forward its own set of franchise system. Jin Cheng International Logistics selects local mature and profitable companies to merge into its group. When choosing partners, it does not require too much of the scale and stock holding. An excellent managerial team is the only requirement to the other party. At the same time, the cooperated company must be renamed, and reunify "Jin Cheng" brand. Using the form of franchise makes many small shipping companies of one-man operation together. They force the "snowball" toward one direction, sharing risks and benefits. Thus it gets a "snowball effect".

\subsection{Develop the third-party logistics enterprises; improve the profession and social level of logistics}

The third-party logistics may enable logistics clients to focus on production, management and cost reduction. Large enterprises, which take the advantages of professional logistics to conduct market distribution, can save the cost of $20 \%$ - 30\% comparing to setting up networks themselves. The third-party logistics can break the geographical boundaries, distribute logistics to long distances, and play the advantage of quick efficiency in e-commerce. Among the World Top 500 enterprises, over 70\% of them think that logistics business should be operated by the third-party logistics. In 1996, the third-party logistics and distribution in U.S.A accounted for $57 \%$ of the total volume. Professional providers of the third-party logistics take the advantages of professions and costs in scale production. Through improving the utilization of each sector's capability, they achieve cost saving and reduce capital backlog, which makes enterprises be benefited from the cost structure. The means of the logistics plans and just-in-time delivery that the third-party logistics providers carefully planned minimize inventory and improve the company's cash flow, and achieve cost advantages.

\subsection{Increase technological investment; improve technological level and circulation efficiency}

Under the support of advanced technology, modern logistics enterprises can directly involve in the logistics management activities. They work out plans together with logistics demanders, and help manufacturers to develop new products, introduce new technologies and new equipments, and so on. For example, Wal-Mart applies a set of advanced and efficient system of logistics and supply chain management. This system centralizes, effectively manages and optimizes Wal-Mart's distribution centers, chain stores, warehouses and cargo transport vehicles worldwide. It forms a flexible and efficient production, distribution and sales network. Therefore, Wal-Mart even spends lots of money and purchase specialized logistics satellite to guarantee the information transmission of this network.

\subsection{Introduce supply chain management; achieve the "win-win"}

It is found that in a competitive environment of globalized market, any enterprise cannot do business in all the best. It must cooperate with other businesses upstream and downstream and establish a supply chain of linking economic interests and having close relationship to achieve complementary advantages, and to fully use available resources to adapt to the competitive environment of socialized large-scale production. This is supply chain management. Considering how to build up supply chain relationship among businesses, that is to create a win-win mechanism. And the key to realize it is information sharing, the core of which is information flow. Introducing supply chain management can take the whole supply chain into consideration, design inventory replenishment and control strategies of supply chain node enterprises, keep inventory at a reasonable level, prevent more or less inventory, meet the needs of production and sales, reduce capital utilization, and keep the lowest total costs of inventory. These will improve enterprises efficiency.

\section{Conclusions}

The general requirements of the State $11^{\text {th }} 5$-Year Development on logistics industry is: taking the scientific outlook on development as guidance, market-oriented, using information technology to support, creating a policy environment of the development of modern logistics, establishing a modern logistics service system with sound and efficient service, vigorously developing the professional and social logistics enterprises, improving the quality and efficiency of logistics services, reducing logistics costs, promoting industrial upgrading and restructuring, providing the corresponding 
logistics security for the economy and society as comprehensive, coordinated, sustainable development and full establishment of a well-off society. It provides the direction of the development of the logistics industry. Meanwhile, it will promote the change of growth mode of circulation economy.

\section{References}

$\mathrm{Hu}$, Jintao. Report in the 17 th National Congress of the CPC.

Lu, Jiang. (2007). Speed up the Development of Modern Economic Circulation. China Business and Market, Vol. 4.

Wang, Zhaofeng. (2003). Strategic Consideration on the Third Party Logistics Based on Electronic Business. Jiangxi Social Sciences, Vol.12.

Wu, Xianhe \& Chen, Shunxia. (2000). Circulation Economics Tutorial. Shanghai: Shanghai University of Finance \& Economics Press.

Wu, Xianhe. (2006). Currency-Oriented: A Valid Way to Change Economic Growth Manner. Shanghai Business, Vol. 1. Yang, Daqing. (2006). The Need of Changing Logistics Growth Mode in the Period of the $11^{\text {th }}$ Five-Year Plan. Modern Logistics Mar, 20. 